\title{
Imaging Lidar systems
}

\section{David Rees}

David Rees, "Imaging Lidar systems," Proc. SPIE 11852, International Conference on Space Optics - ICSO 2020, 118526C (11 June 2021); doi: $10.1117 / 12.2600286$

SPIE. Event: International Conference on Space Optics - ICSO 2021, 2021, Online 


\section{International Conference on Space Optics-ICSO 2020}

Virtual Conference

30 March-2 April 2021

Edited by Bruno Cugny, Zoran Sodnik, and Nikos Karafolas
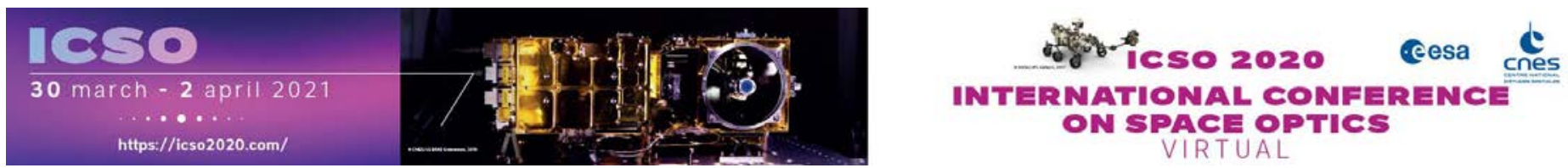

\section{Imaging Lidar systems}

\section{Cesa isopmeatians ecnes}

International Conference on Space Optics - ICSO 2020, edited by Bruno Cugny, Zoran Sodnik, Nikos Karafolas, Proc. of SPIE Vol. 11852, 118526C · (c) 2021 ESA and CNES

CCC code: $0277-786 \mathrm{X} / 21 / \$ 21 \cdot$ doi: $10.1117 / 12.2600286$ 


\section{Imaging Lidar SYSTEMS \\ Rees; David; The Paradigm Factor Ltd.}

Laser Altimeters have been used in space and ground-based / aircraft applications for many years. This presentation concentrates on recent technology developments and the possibility of exploiting the laser ranging technique in a multitude of relatively new areas:

- Bathymetry (measurement of the sea depth in shallow water zones);

- Canopy (distribution of the scattering elements from the top of canopy down to the ground);

- Snow depth mapping and ice thickness mapping;

- Global 3-D imaging.

These applications can all exploit high rep-rate multi-beam laser systems with multi-element photon-counting detector arrays with appropriate high-precision timing and image reconstruction to provide high-resolution 3-D images of the sub-orbital path. The ability of Imaging Lidar to penetrate cloud and other obscurations can also be exploited.

\begin{tabular}{|l|l|} 
The "traditional" Laser Altimeter operates as on the left, \\
the return signal from a low re-rate, high power laser, with \\
analogue signal detection picks up only the $1^{\text {st }}$ return - \\
whether from ice, snow, vegetation or the ground / sea- \\
surface. \\
The development of multi-element photon-counting \\
detectors allows major improvements in spatial and range \\
resolution: \\
- Not only can the Forest Canopy be detected, but the \\
distribution of all structural (scattering) elements from the \\
top of the canopy down to ground-level can be sensed.
\end{tabular}

Figure 1:

- These abilities can be extended to the bathymetry of surface water over land areas and the study of sub-surface regions to depths of order $50-100$ metres in the Continental Margins.
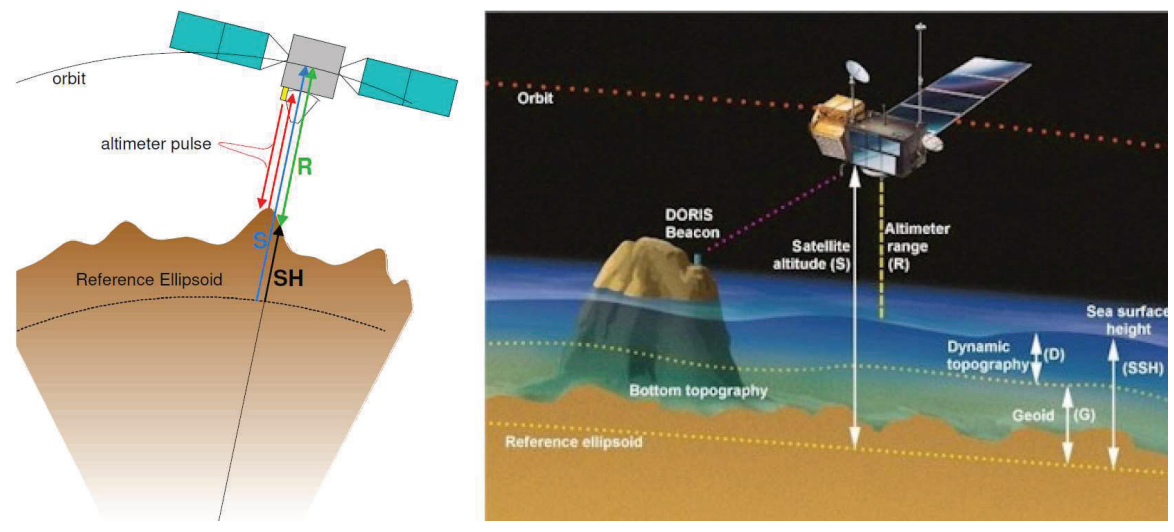

Figure 2: 
Table 1: Some Previous Space Missions Exploiting Laser Altimeters

\begin{tabular}{|l|c|c|c|c|c|c|}
\hline Mission & $\begin{array}{l}\text { Clementine } \\
\text { (NASA) }\end{array}$ & $\begin{array}{l}\text { NEAR } \\
\text { (NASA) }\end{array}$ & $\begin{array}{l}\text { Mars Global } \\
\text { Surveyor (NASA) }\end{array}$ & $\begin{array}{l}\text { ICESat } \\
\text { (NASA) }\end{array}$ & $\begin{array}{l}\text { MESSENGER } \\
\text { (NASA) }\end{array}$ & $\begin{array}{l}\text { BepiColombo } \\
\text { (ESA) }\end{array}$ \\
\hline Launch year & 1994 & 1996 & 1996 & 2003 & 2004 & $\begin{array}{c}2014 \\
\text { (planned) }\end{array}$ \\
\hline Destination & Moon & 433 Eros & Mars & Earth & Mercury & Mercury \\
\hline $\begin{array}{l}\text { Laser } \\
\text { Altimeter }\end{array}$ & $\begin{array}{c}\text { Laser ranging } \\
\text { system }\end{array}$ & NLR & MOLA & GLAS & MLA & BELA \\
\hline Application & $\begin{array}{c}\text { Moon } \\
\text { topography }\end{array}$ & $\begin{array}{c}\text { Asteroid } \\
\text { topography }\end{array}$ & $\begin{array}{c}\text { Mars } \\
\text { topography }\end{array}$ & $\begin{array}{c}\text { Ice-sheet } \\
\text { topography }\end{array}$ & $\begin{array}{c}\text { Topography, } \\
\text { Gravimetry }\end{array}$ & $\begin{array}{c}\text { Topography, } \\
\text { Gravimetry }\end{array}$ \\
\hline $\begin{array}{l}\text { Altimeter } \\
\text { wavelength }\end{array}$ & $1064 \mathrm{~nm}$ & $1064 \mathrm{~nm}$ & $1064 \mathrm{~nm}$ & $1064 \mathrm{~nm}$ & $1064 \mathrm{~nm}$ & $1064 \mathrm{~nm}$ \\
\hline $\begin{array}{l}\text { Pulse } \\
\text { energy }\end{array}$ & $171 \mathrm{~mJ}$ & $15.3 \mathrm{~mJ}$ & $42 \mathrm{~mJ}$ & $75 \mathrm{~mJ}$ & $20 \mathrm{~mJ}$ & $50 \mathrm{~mJ}$ \\
\hline $\begin{array}{l}\text { Repetition } \\
\text { frequency }\end{array}$ & $0.6 \mathrm{~Hz}$ & $1 \mathrm{~Hz}$ & $10 \mathrm{~Hz}$ & $40 \mathrm{~Hz}$ & $8 \mathrm{~Hz}$ & $10 \mathrm{~Hz}$ \\
\hline $\begin{array}{l}\text { Telescope } \\
\text { aperture } \varnothing\end{array}$ & $130 \mathrm{~mm}$ & $90 \mathrm{~mm}$ & $500 \mathrm{~mm}$ & $1000 \mathrm{~mm}$ & $\begin{array}{c}106 \mathrm{~mm} \\
\text { apertures })\end{array}$ & $250 \mathrm{~mm}$ \\
\hline
\end{tabular}

Illustration of the historical « analogue » laser altimeter systems

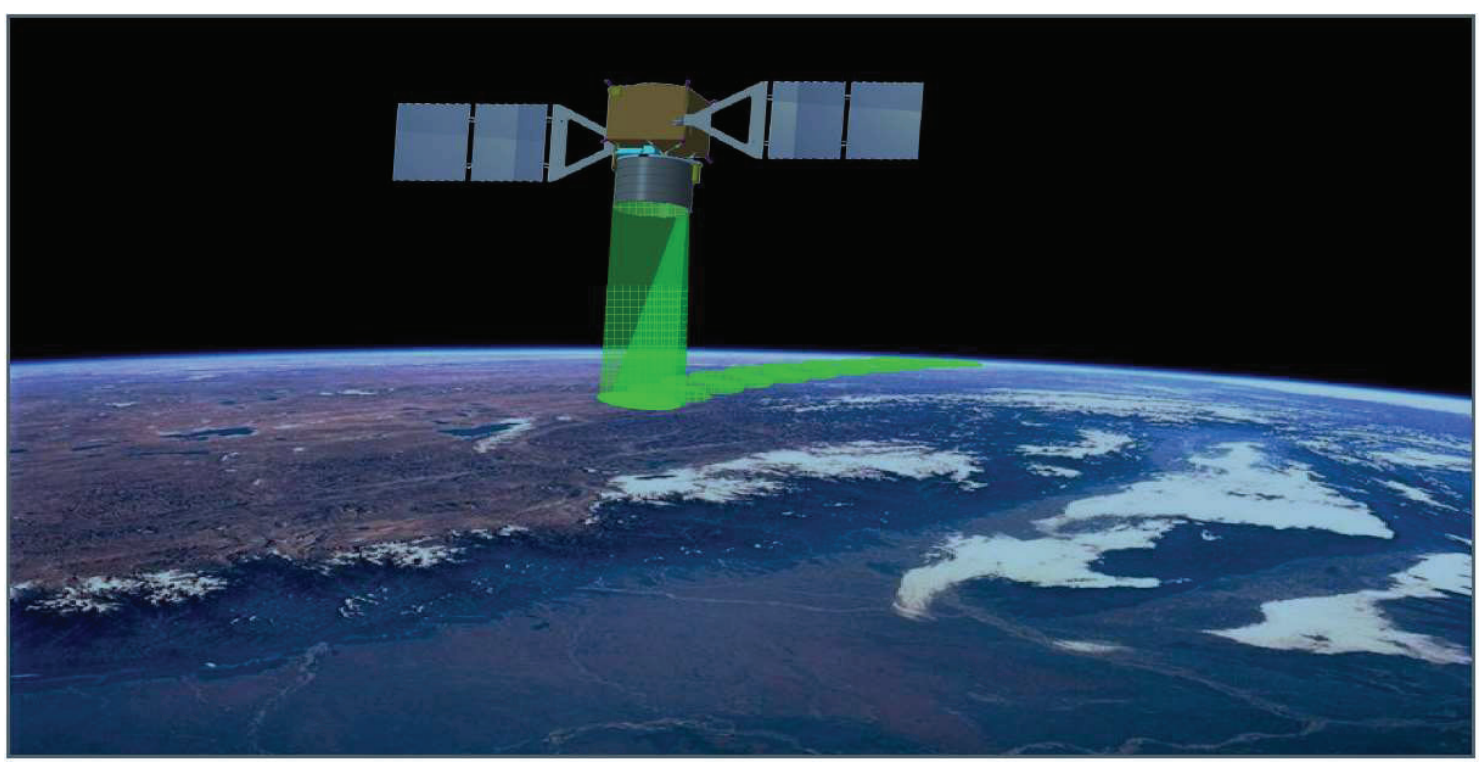

Using a relatively large " spot size » and low repetition rate, the ground resolution of analogue laser altimeter systems is limited to a few hundred metres 


\section{Clouds/aerosol characterization from ICESat data}
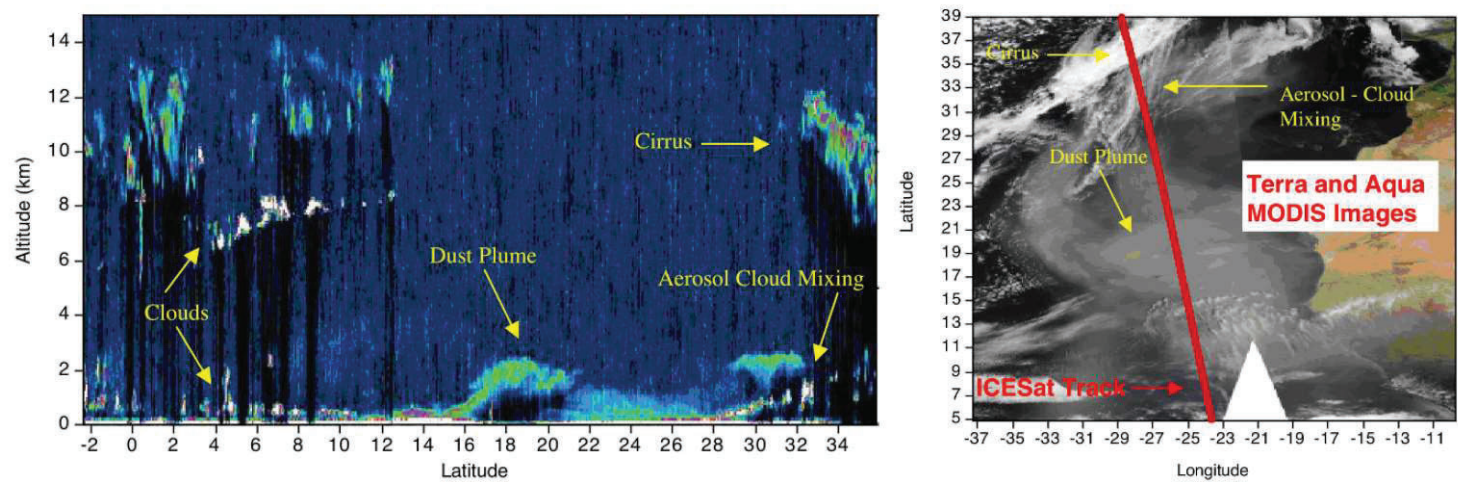

The image at left illustrates the sophisticated range of atmospheric measurements obtainable from an altimeter system such as ICESAT.

The image at right is combined from MODIS data covering the track.

\section{Greenland Height change map (ICESat) Mass Change (GRACE).}

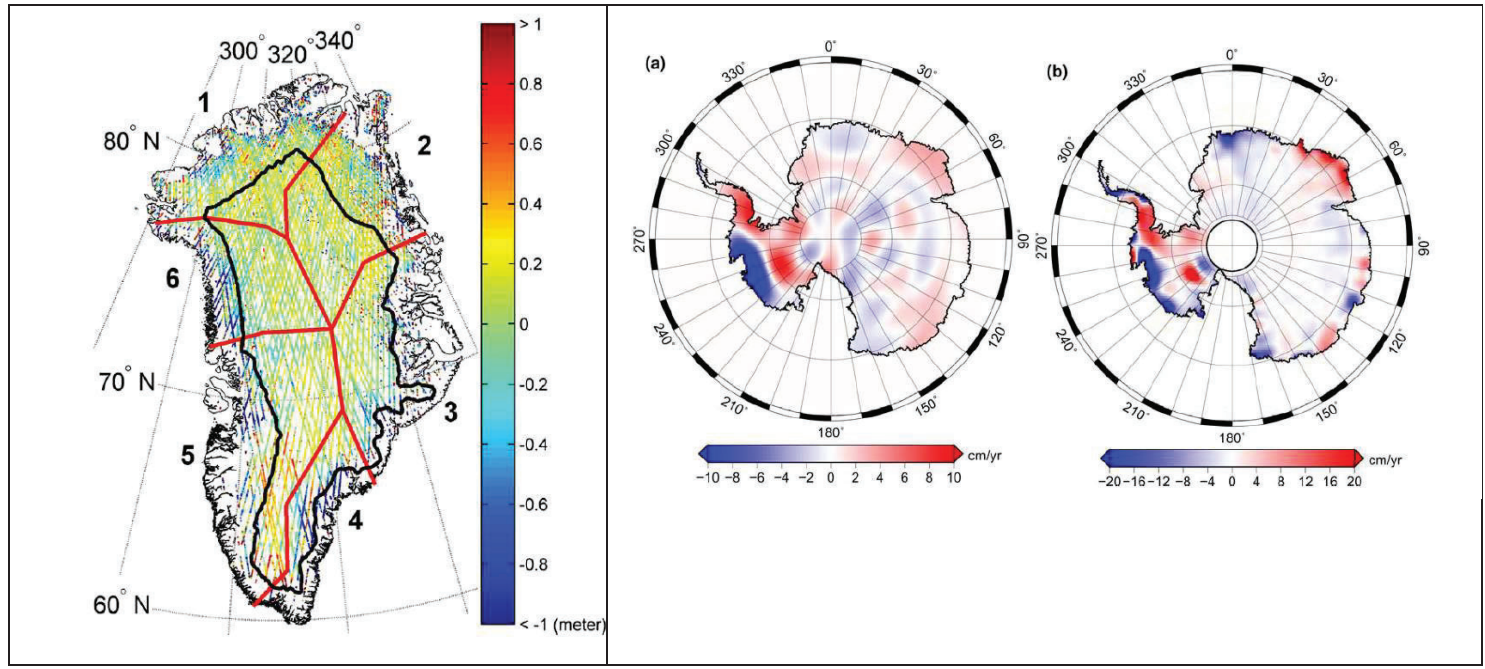




\section{Conceptual illustration of laser ranging approaches}

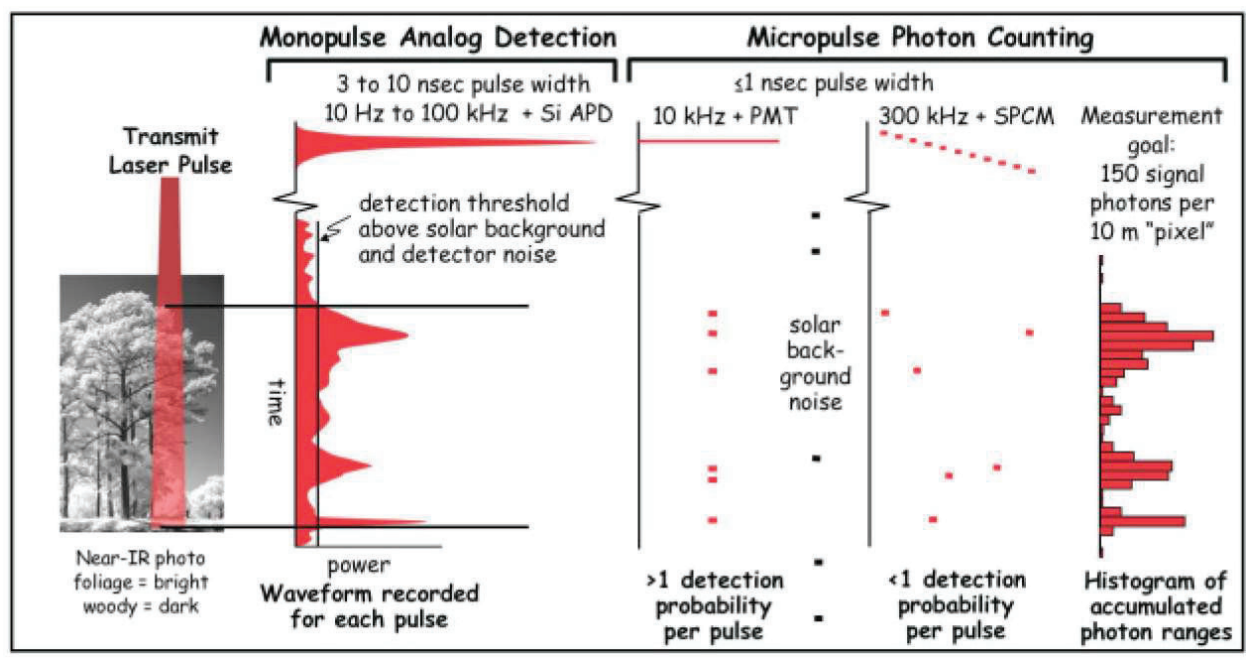




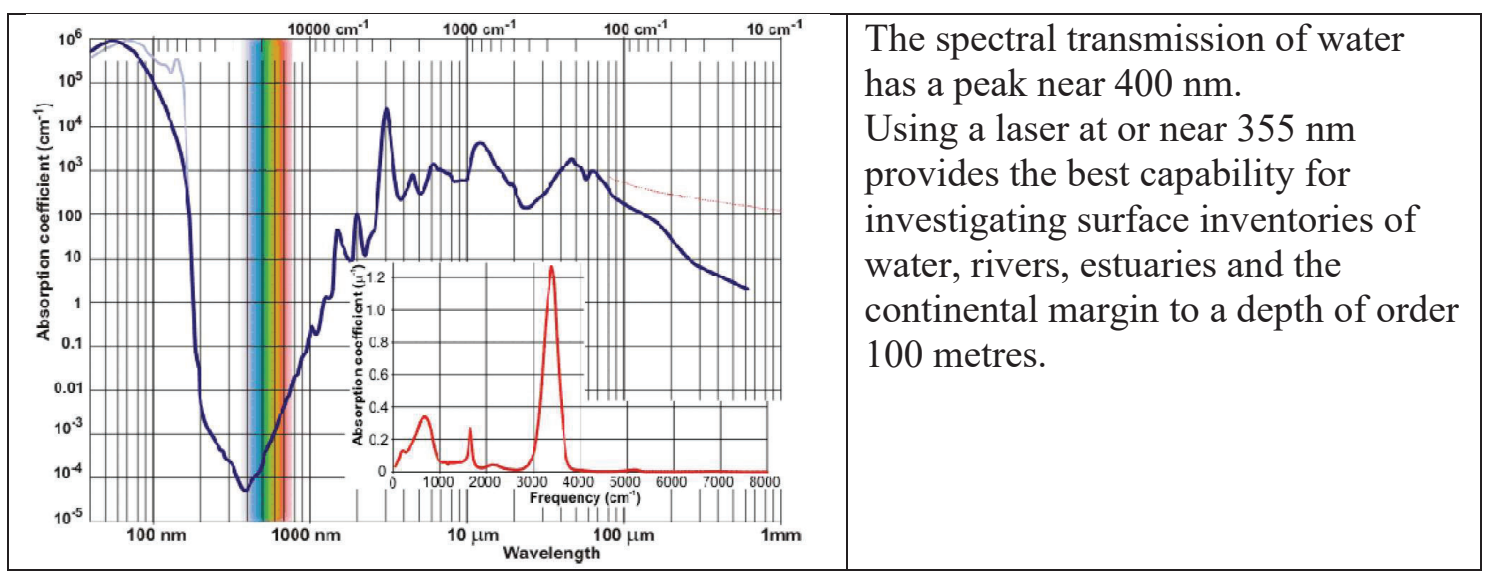


Operational Requirements - footprint / beam divergence

\begin{tabular}{|c|c|c|c|c|c|c|}
\hline \multirow[t]{2}{*}{ Application } & \multicolumn{3}{|c|}{ Footprint [m] } & \multicolumn{3}{|c|}{ Beam divergence [ $\mu \mathrm{rad}]$} \\
\hline & Threshold & Breakthrough & Objective & Threshold & Breakthrough & Objective \\
\hline $\begin{array}{l}\text { Altimetry - Land } \\
\text { topography }\end{array}$ & 100 & 50 & 1 & 250 & 125 & 2.5 \\
\hline $\begin{array}{l}\text { Altimetry - Global ocean } \\
\text { topography }\end{array}$ & $100 \mathrm{~km}$ & $50 \mathrm{~km}$ & $1 \mathrm{~km}$ & $250 \mathrm{mrad}$ & $125 \mathrm{mrad}$ & $2.5 \mathrm{mrad}$ \\
\hline $\begin{array}{l}\text { Altimetry - Ocean } \\
\text { bathymetry }\end{array}$ & $25 \mathrm{~km}$ & $10 \mathrm{~km}$ & $1 \mathrm{~km}$ & $62.5 \mathrm{mrad}$ & $25 \mathrm{mrad}$ & $2.5 \mathrm{mrad}$ \\
\hline $\begin{array}{l}\text { Altimetry - River/lake } \\
\text { height }\end{array}$ & 500 & 200 & 10 & $1.25 \mathrm{mrad}$ & 500 & 25 \\
\hline Shallow Water Bathymetry & 25 & 2.5 & 1 & 62.5 & 6.25 & 2.5 \\
\hline Vegetation canopy & 50 & 25 & 5 & 125 & 62.5 & 12.5 \\
\hline $\begin{array}{l}\text { Ice/snow thickness } \\
\text { mapping }\end{array}$ & 50 & 50 & 5 & 125 & 125 & 12.5 \\
\hline Fluorescent measurements & 50 & 25 & 5 & 125 & 62.5 & 12.5 \\
\hline $3 \mathrm{D}$ imaging & 100 & 30 & 10 & 250 & 75 & 25 \\
\hline
\end{tabular}

Misson Requirements for Advanced Altimeters for Terrestrial, lunar and Planetary Missions

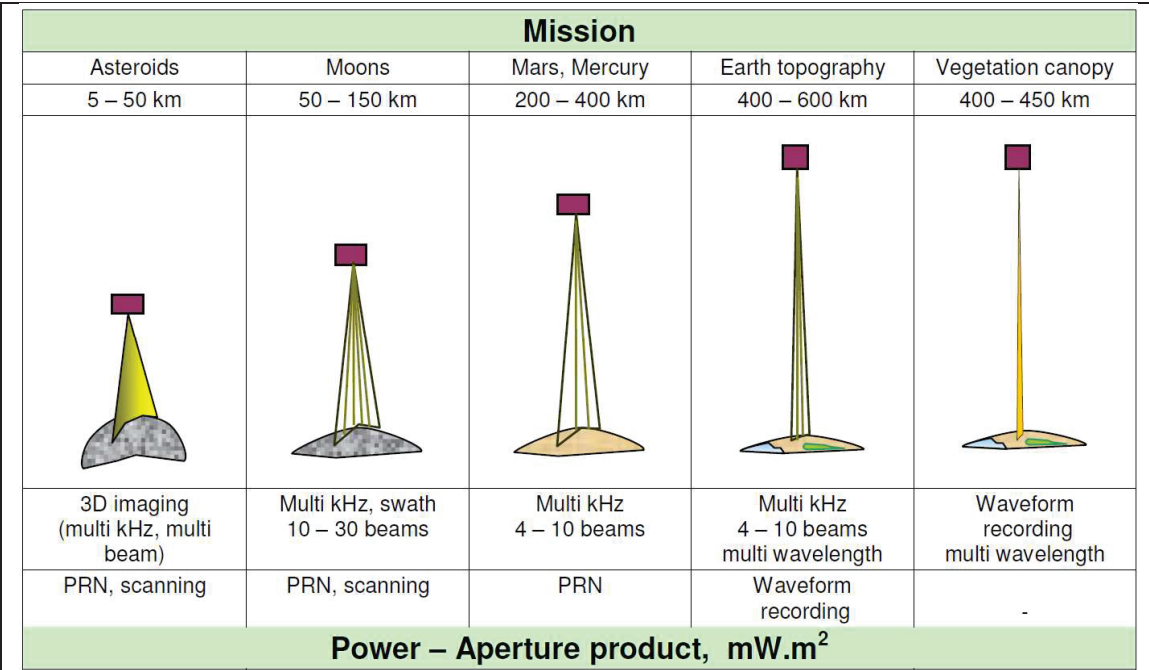

Multi-beam laser altimeter systems have crucial roles to play in many cutting-edge fields of space research. 
CryoSat-2 (top) and IceSat-2 (bottom)

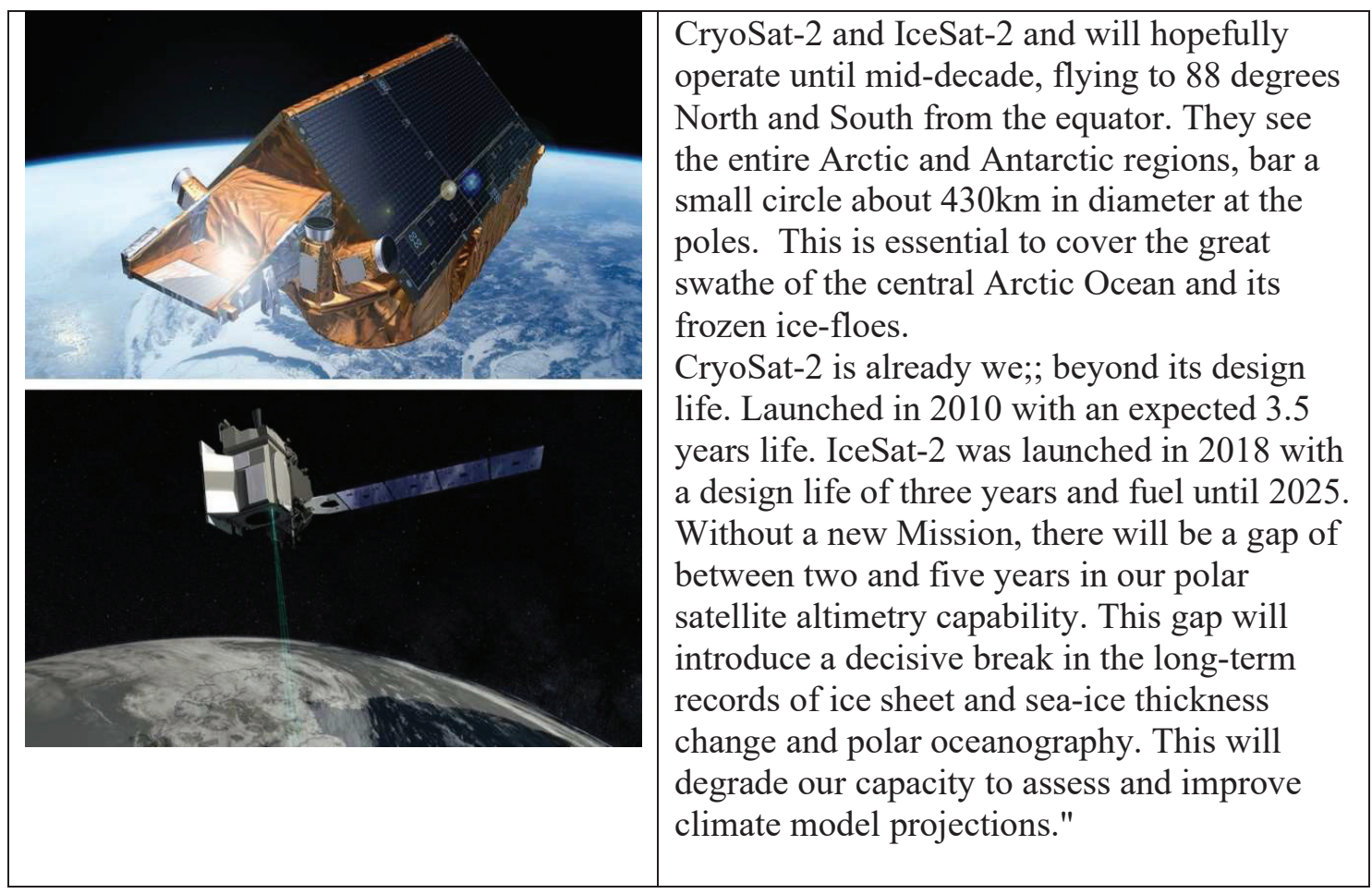

\section{LOLA - Lunar Orbiter Laser Altimeter}
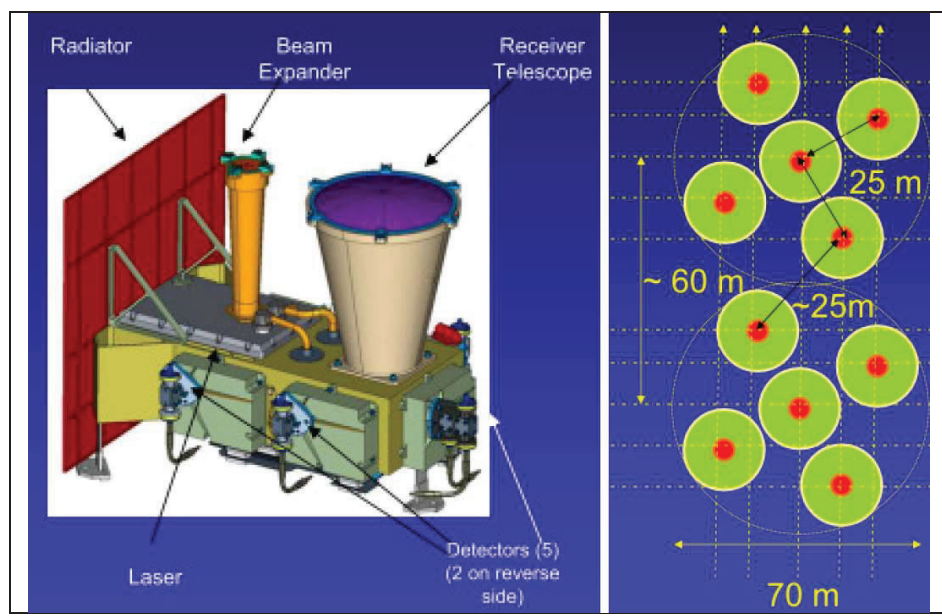

LOLA will exploit a multibeam laser altimeter systems to meet its objectives in studying the lunar surface in unparalleled detail

What can an Imaging Lidar System provide?

Given a clear atmospheric conditions or cloudy / foggy conditions:

$>$ Full 3-D instantaneous structure of everything within the field of view of the Imaging Lidar:-

$>$ Range for every identifiable object;

$>$ Velocity (speed + direction) for every object; 
Detection, and Identification are subject to the normal rules of optical resolution / distance and signal to noise ratio etc.

Fog and cloud causes blurring and diffusion in normal vision.

How does the Imaging Lidar avoid this?

The negative effects of a foggy or cloudy atmosphere on normal vision and imaging are familiar:-

$>$ The outlines of objects quickly become blurred;

> Identification becomes difficult / impossible;

$>$ Beyond $\sim 3$ optical thicknesses even the outlines disappear into the fog or cloud.

The Imaging Lidar circumvents the blurring and diffusion caused by fog and cloud by the combining of temporal and spectral filtering with image deconvolution.

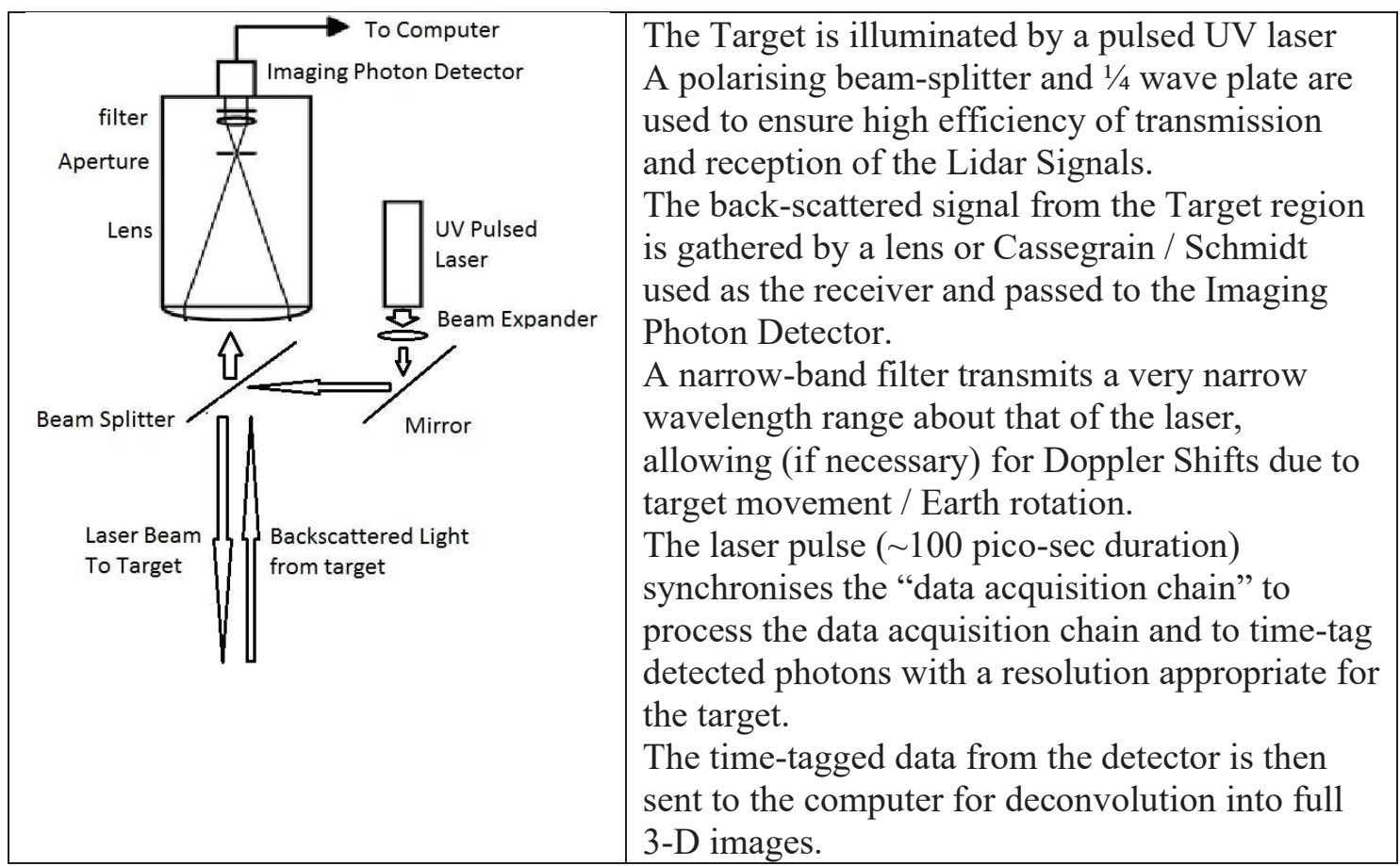




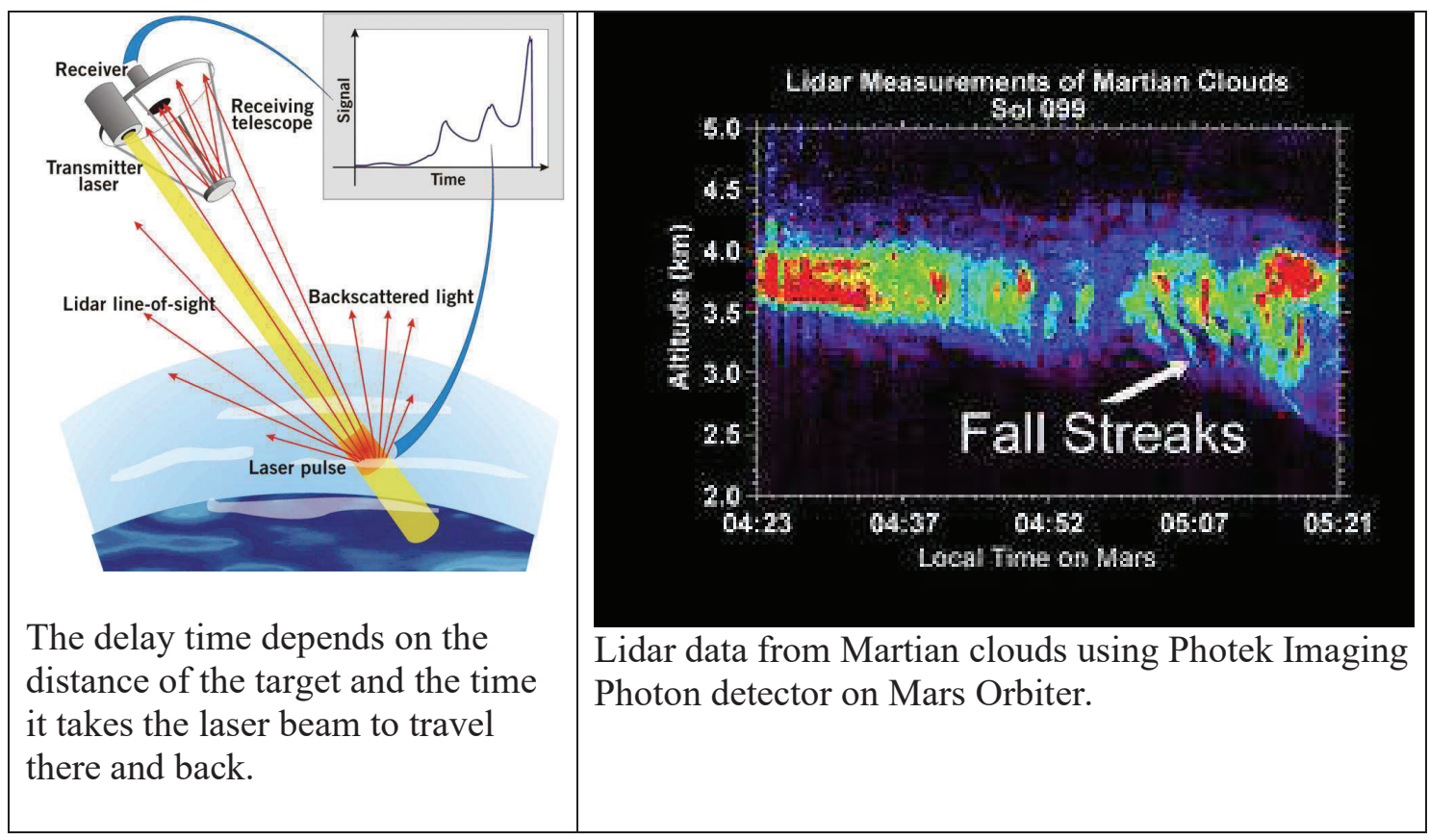

The Laser fires a pulse towards
target.
The backscattered light from fog
/ cloud is ignored by detector
while gate closed.
$\begin{aligned} & \text { The Reflected pulse is imaged } \\ & \text { by detector. Gate (shutter) } \\ & \text { opened to just allow light from } \\ & \text { range of interest to be collected. }\end{aligned}$




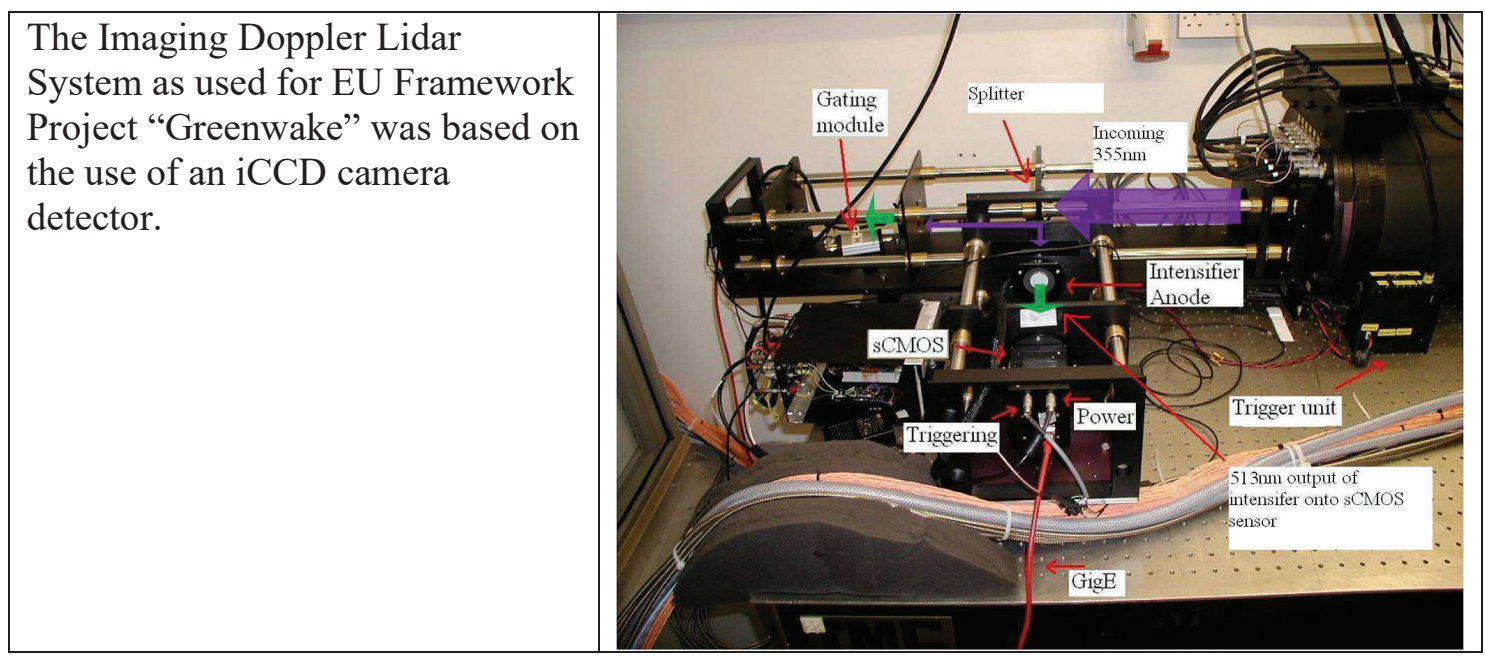

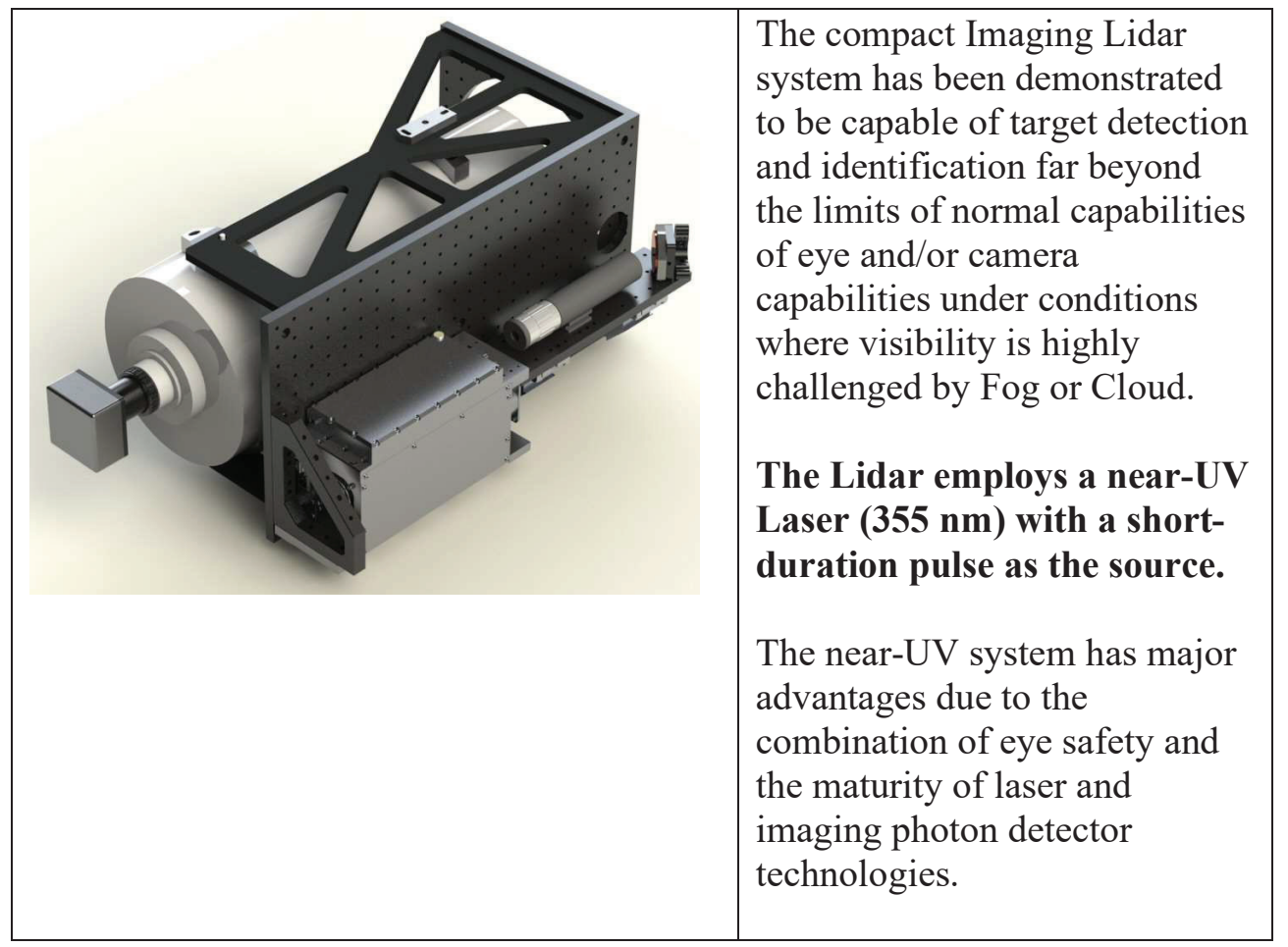




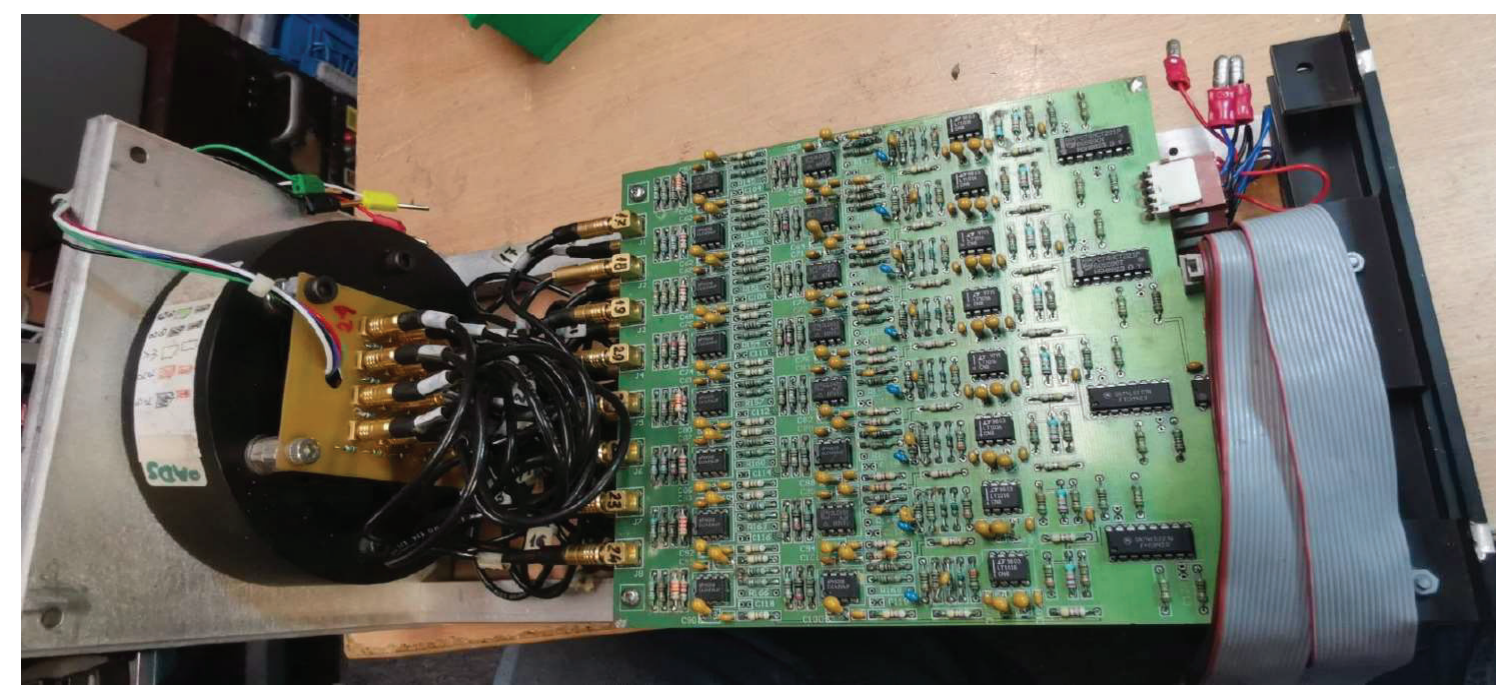

The UV-sensitive photocathode detects single photons (individual light particles), converting them into photoelectrons.

Gating (or electronic shuttering) at a few nanoseconds duration of the photocathode controls the effective viewingrange of the system. (Rule of thumb: Light travels $1 \mathrm{~m}$ in about 3.3 nsec - one way - or $6.7 \mathrm{nsec}$ for the round-trip exploited by Lidar)
High gain microchannel plates allow individual photo-electron bursts to be amplified by multiplication.

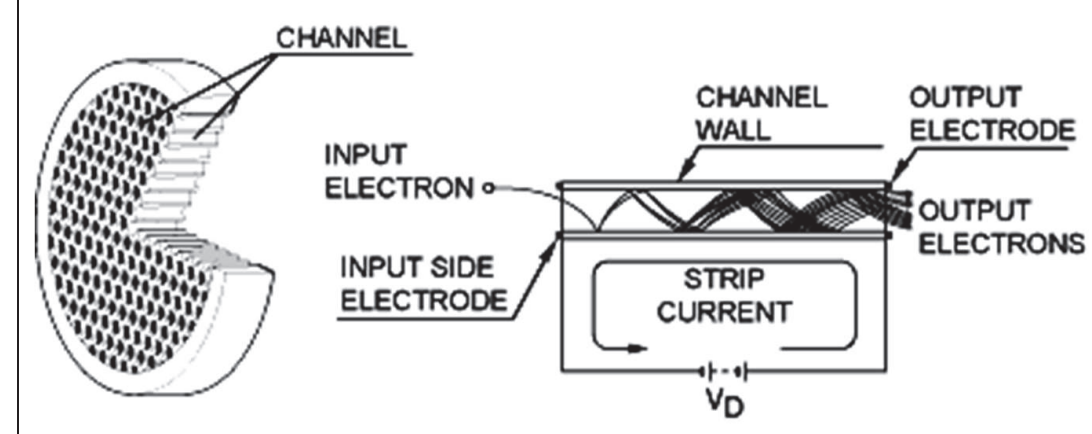


The electron cloud hits the positionsensitive anode which splits the signal into 1024 blocks in a $32 \times 32$ grid.
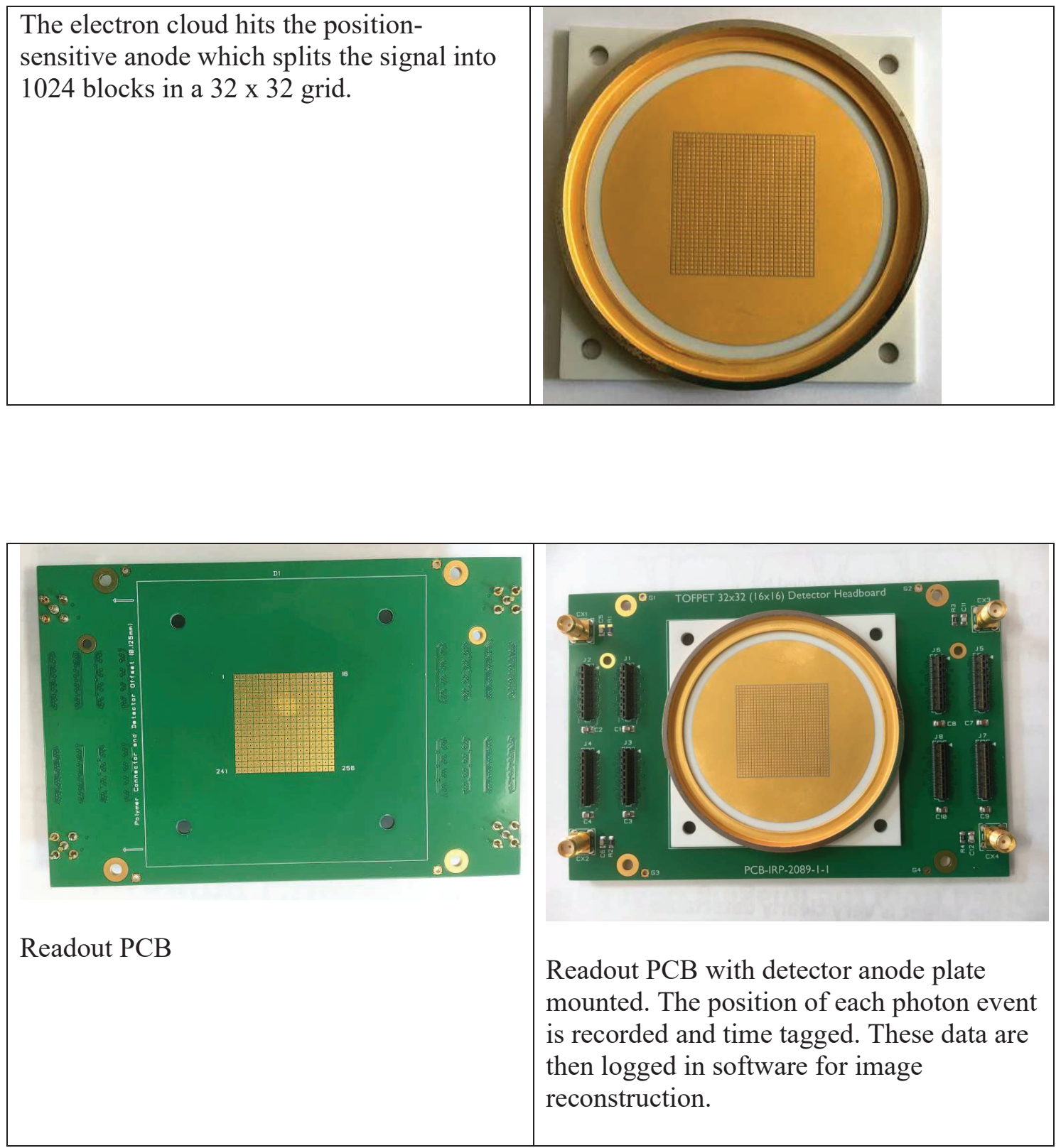
Logarithmic presentation of Signal from Target behind Cloud.

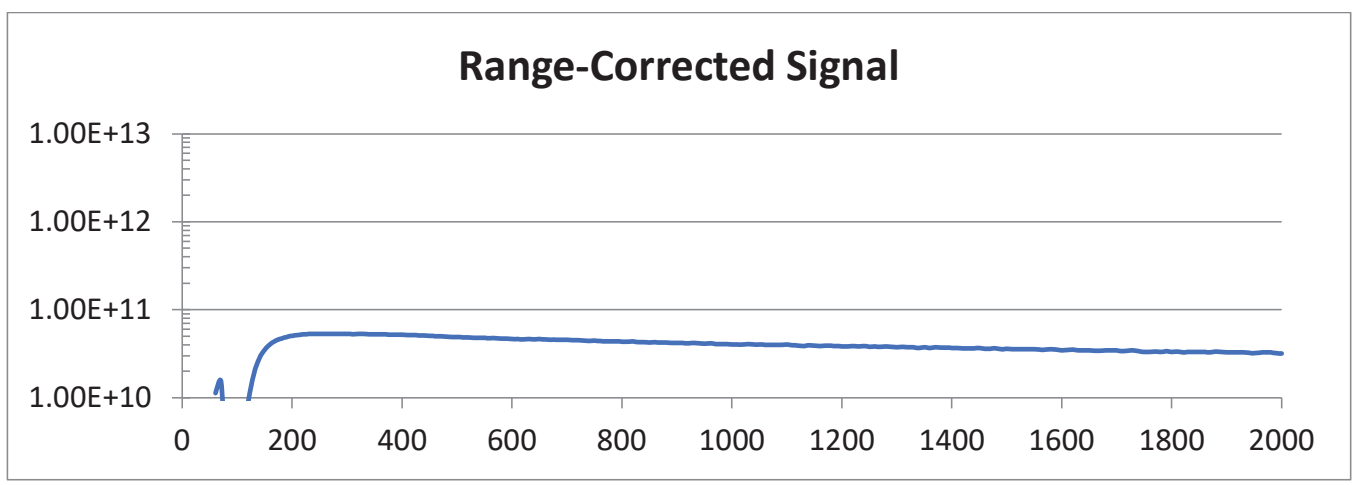

Clear Atmosphere:

The signal, range-corrected, drops off slowly due to attenuation and the decrease of atmospheric density with altitude. The "clear sky" signal is slightly lower than when a cloud layer is present.

\section{Logarithmic presentation of Signal from Target behind Cloud.}

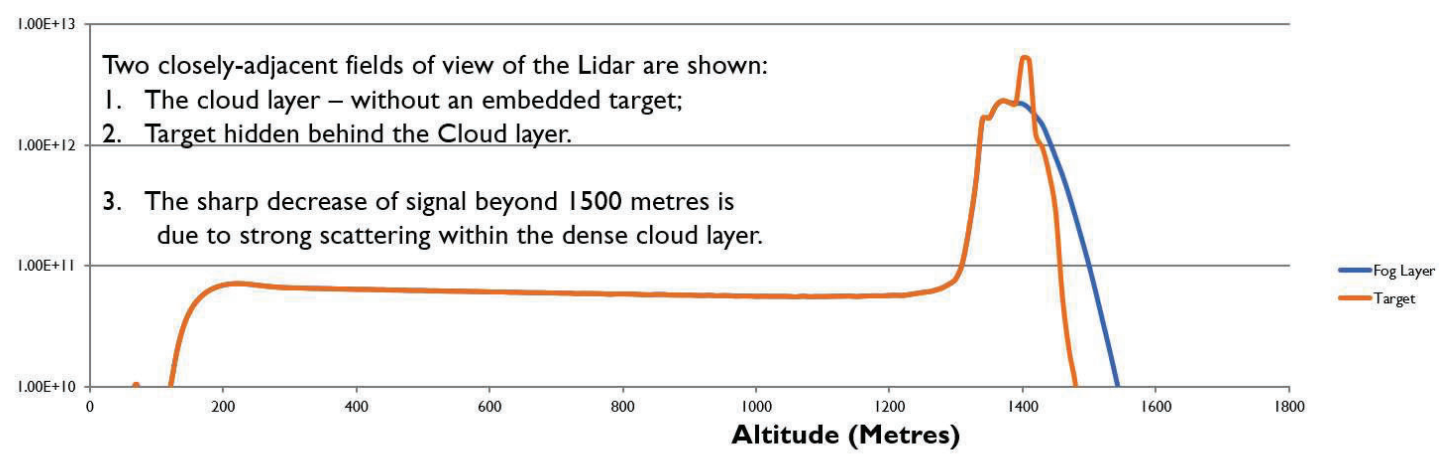



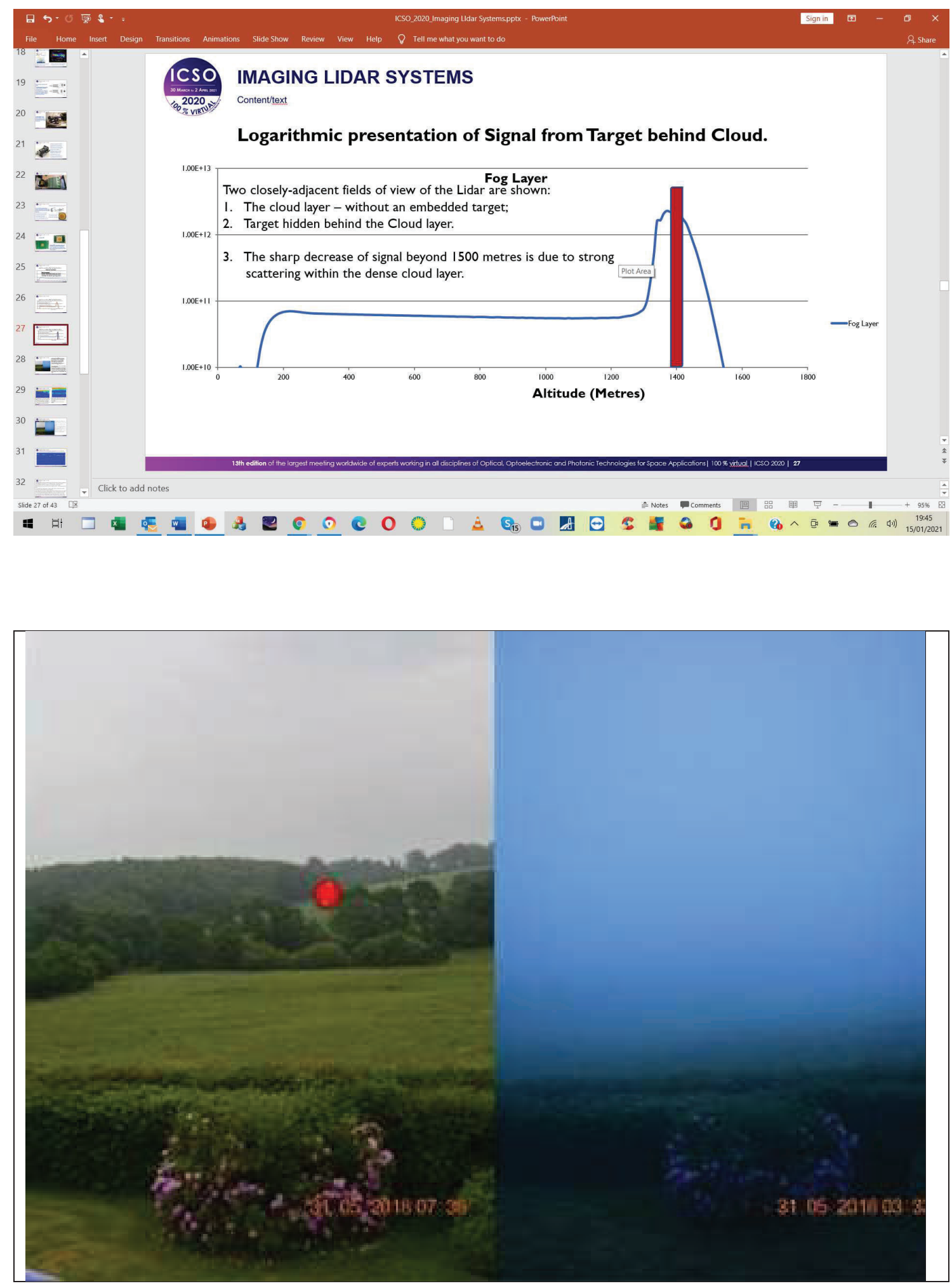

In addition to producing 3-D images of the distant field, the imaging Lidar - when using a 2$\mathrm{D}$ imaging photon detector with $100 \mathrm{psec}$ time-tagging has a remarkable capability for 
detecting and imaging targets through cloud and fog, well beyond the visibility offered by eye or normal camera.

A standard Nikon Camera shows the comparative views under clear and foggy conditions.

A best estimate of normal "visibility" in the fog (right) is between $30-50$ metres.

The following images demonstrate the capability of the Imaging Lidar to not only image the far field in 3-D, but also to provide essentially the same information when the visibility is severely compromised by heavy fog. The red spot covers trees at a distance of 600 metres. This is some 12 times the "visibility" as indicated by the camera images!

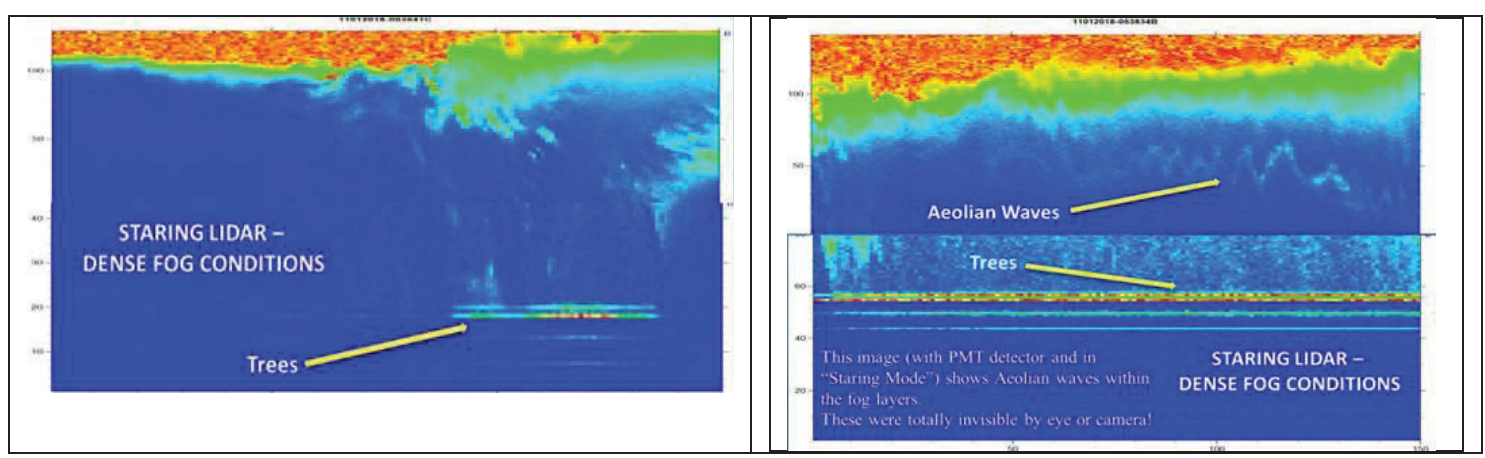

This image shows the back-scattered signal from the lidar when used with a conventional PMT detector and operated in "Staring" Mode. Time is running from left to right - the $1 \mathrm{~km}$ distant trees appear through heavy mist - having been obscured, even to the Lidar, earlier
The Imaging Lidar shows Aeolian Waves well-hidden (by eye / camera) within the fog layer. The "visibility conditions" were those of the earlier image.

( $<50$ metres "visibility" by either eye or camera).

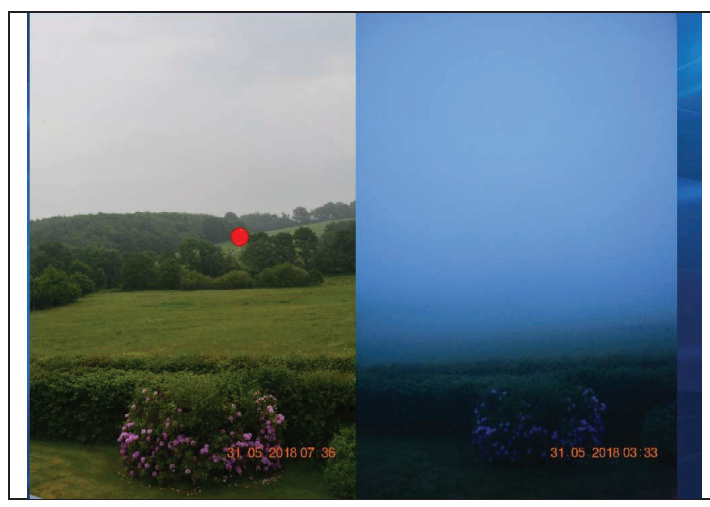

The image on the left shows the "normal" appearance of this field of view.

At right is the contrasting "foggy" image A red circle indicates the centre of the fov of the Imaging Lidar System and the approximate region illuminated by the beam-expander of the UV laser $(355 \mathrm{~nm})$. The region illuminated is centred on the foliage of a large Oak tree. 


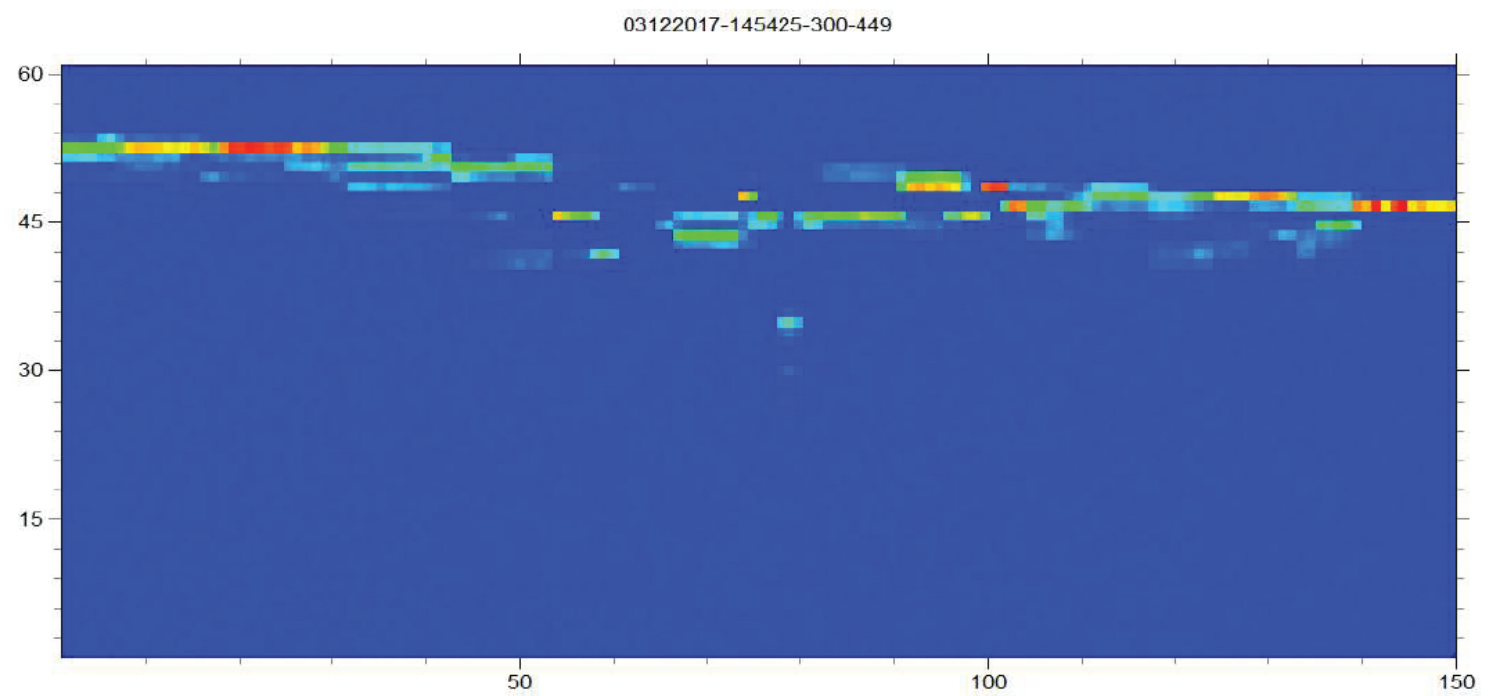

Scanning Lidar System with PMT detector - observing trees etc at $\sim 800-1000$ metres.

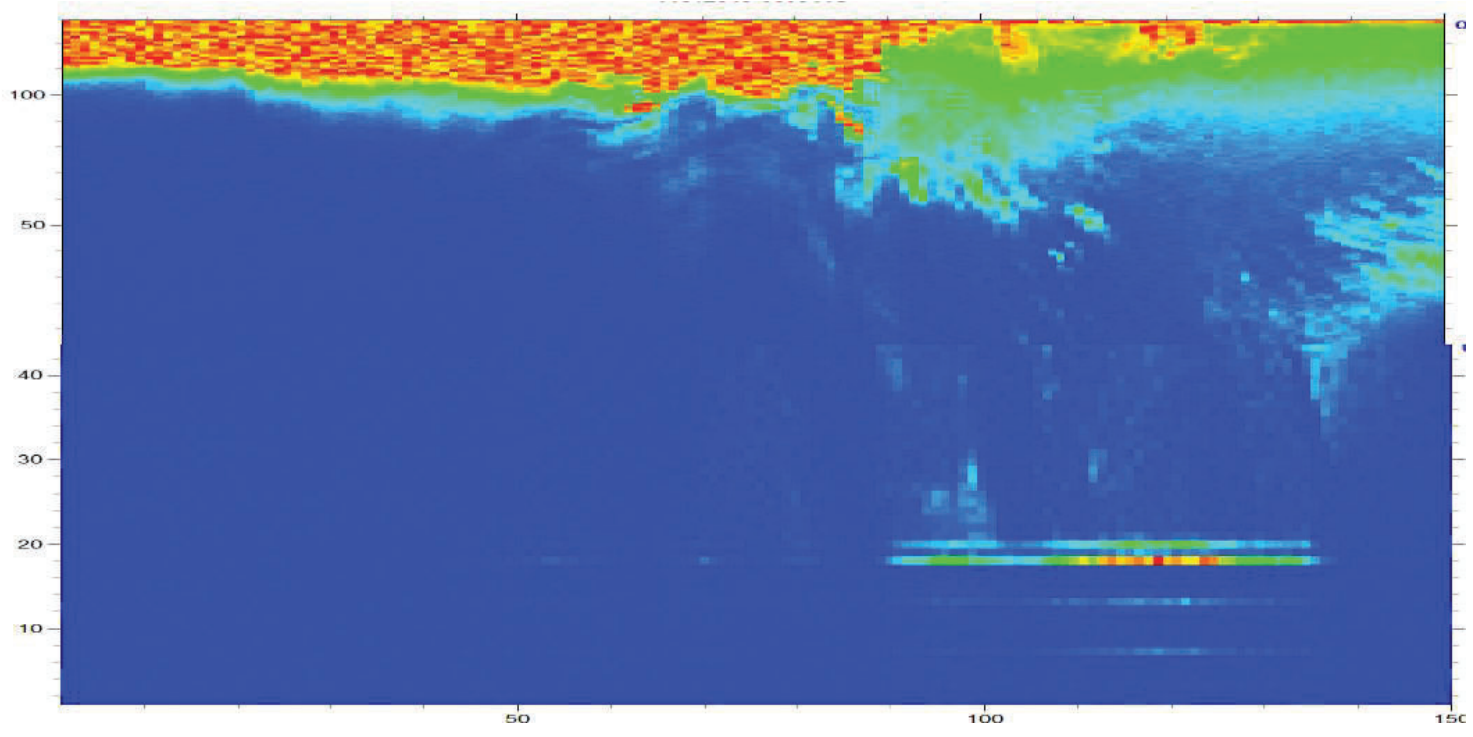

This image shows the back-scattered signal from the lidar used with a conventional

PMT detector and operated in a 2-D "Scanning Mode". Horizontal distance (perpendicular to the line-of-sight) is now running from left to right.

The structures are trees and fence-posts at distances of $800-1000$ metres from the lidar. 


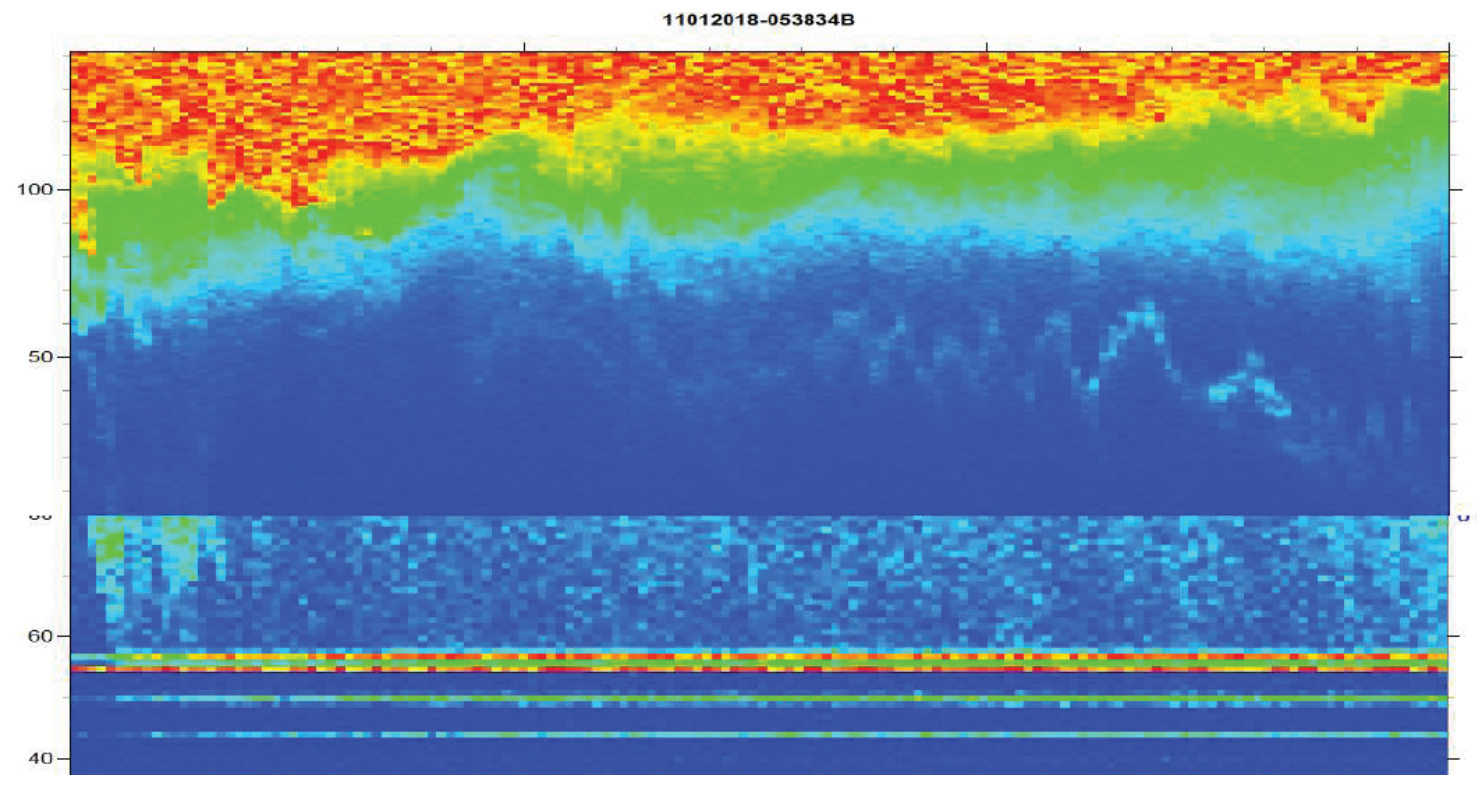

This image PMT detector and in "Staring Mode" shows Aeolian waves within the fog. All totally invisible by eye or camera!!

« Staring » lidar observing trees / fences at 800 metres through dense mist / fog.

The image shows the propagation of Aeolian waves along the valley, within the fog layer.

These features were totally invisible by eye or to a normal camera.

Zero Range is at top!

This image shows the back-scattered signal from the lidar used with a conventional

PMT detector and operated in "Staring Mode". Time is running from left to right.

The zero range for the atmospheric signal at short range is at the top, showing dense fog at the start, clearing slightly in the period to the right. A range of tree / fence structures are then visible (near bottom), despite the continuous but slightly less dense fog. 


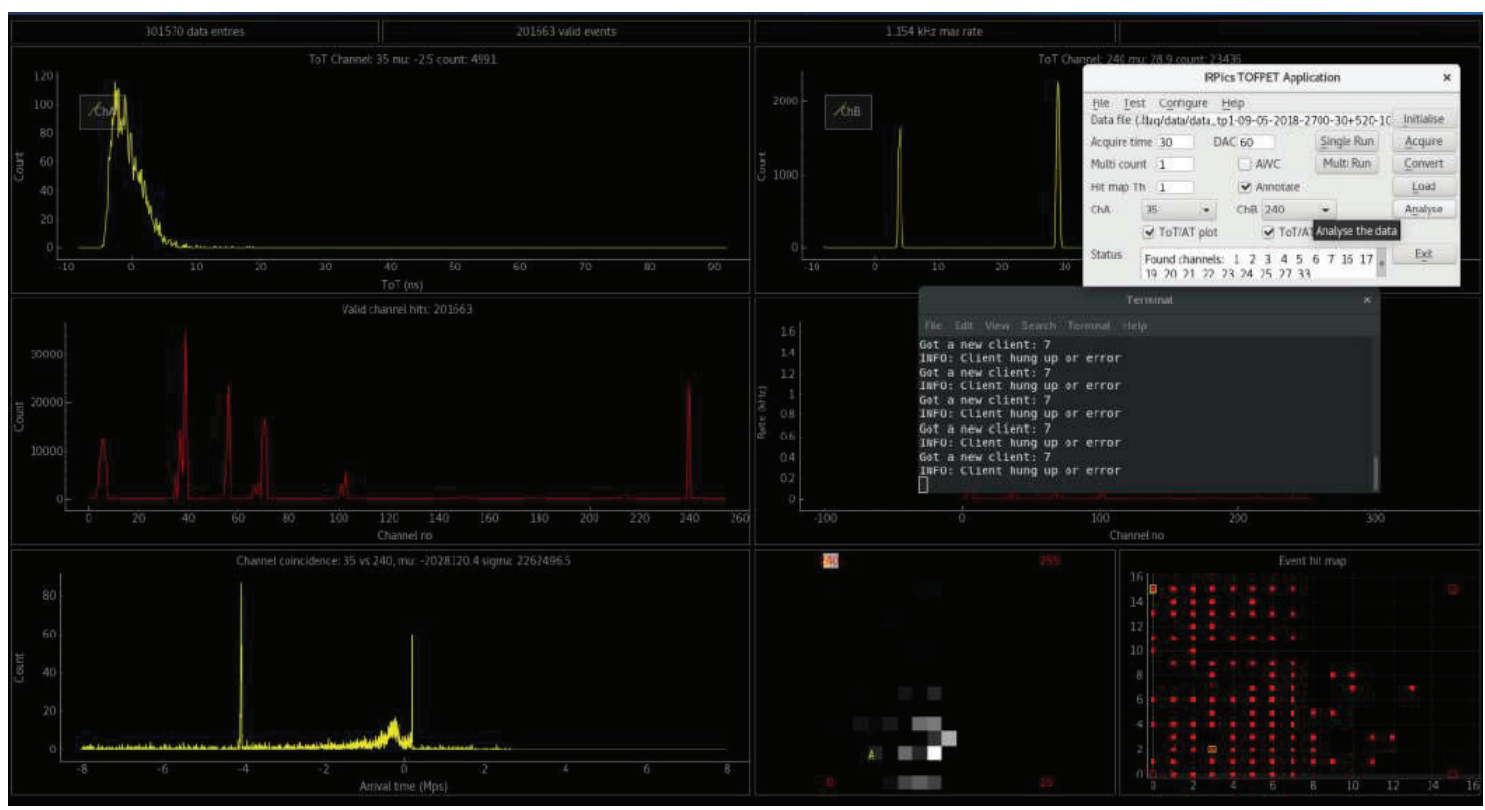

Signal versus range.

Image - the white spot is a tree at 600 metres

There is a weak "clear sky" atmospheric signal at short range.

There is a strong signal return from the tree at $4 \mathrm{msec}$ (to left).

The "atmospheric" signal is also present.

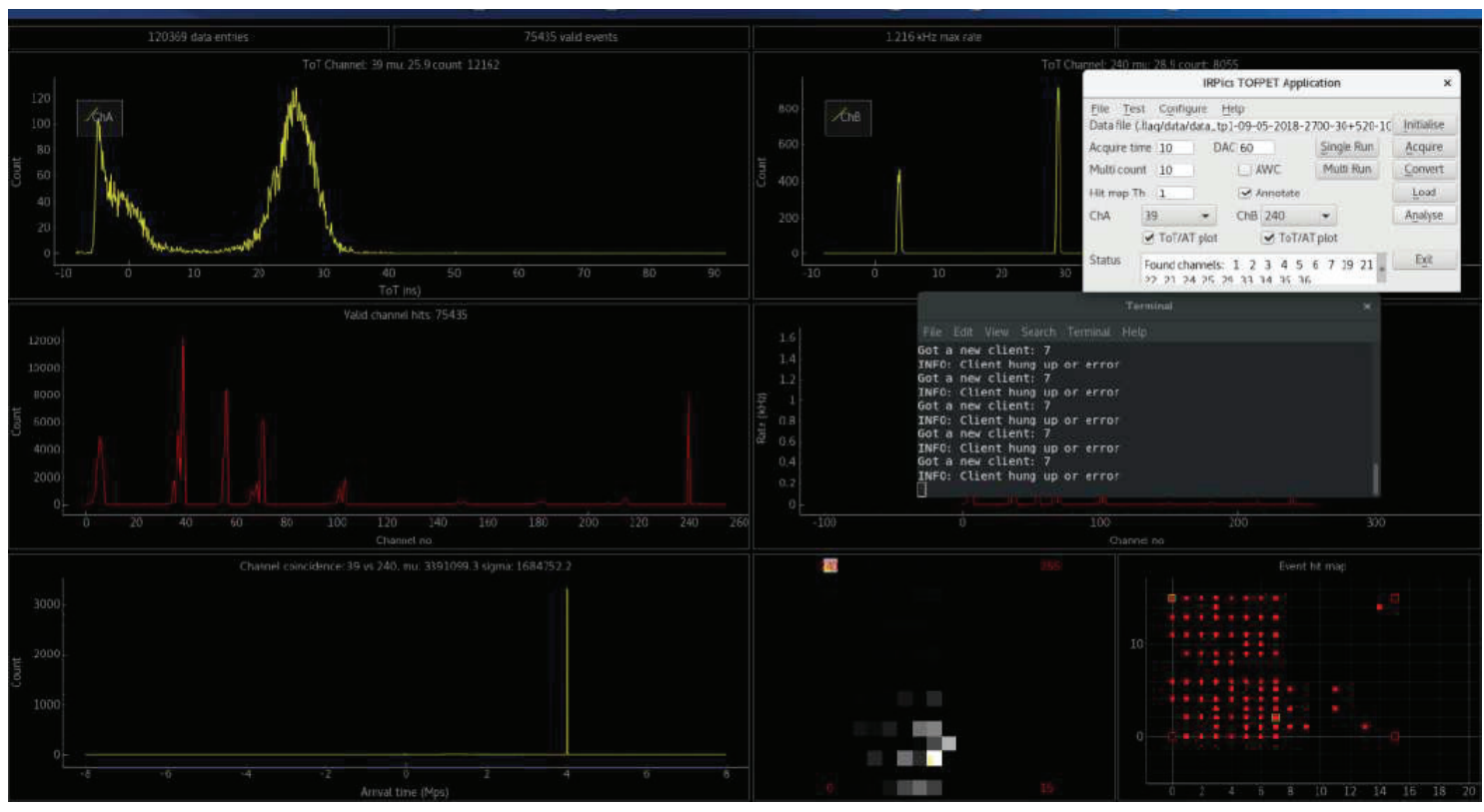

Signal versus range.

Image - the white spot is a tree at 600 metres

The "clear sky" atmospheric signal at short range is totally dominated by the return from a tree.

This is the very strong signal return at $4 \mathrm{msec}$ (to right) from the tree 


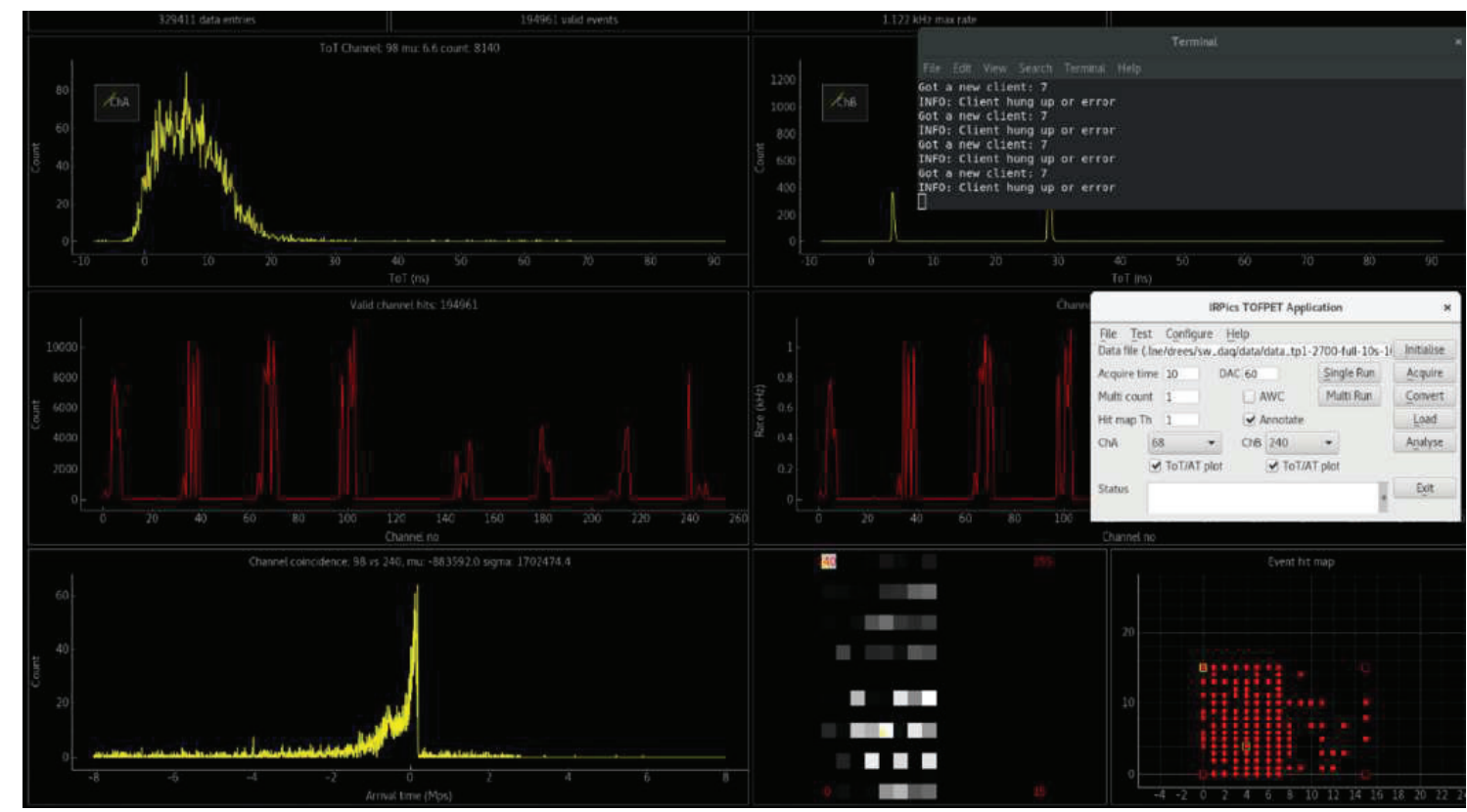

Signal versus range. Image - the white spot (37) is a tree at 600 metres.

This image shows the back-scattered signal return from pixel 37.

The atmospheric signal at short range is strong (enhanced by the mist / fog).

There is a weak but easily measured signal return at $\sim 4$ msec (to right) from the tree.

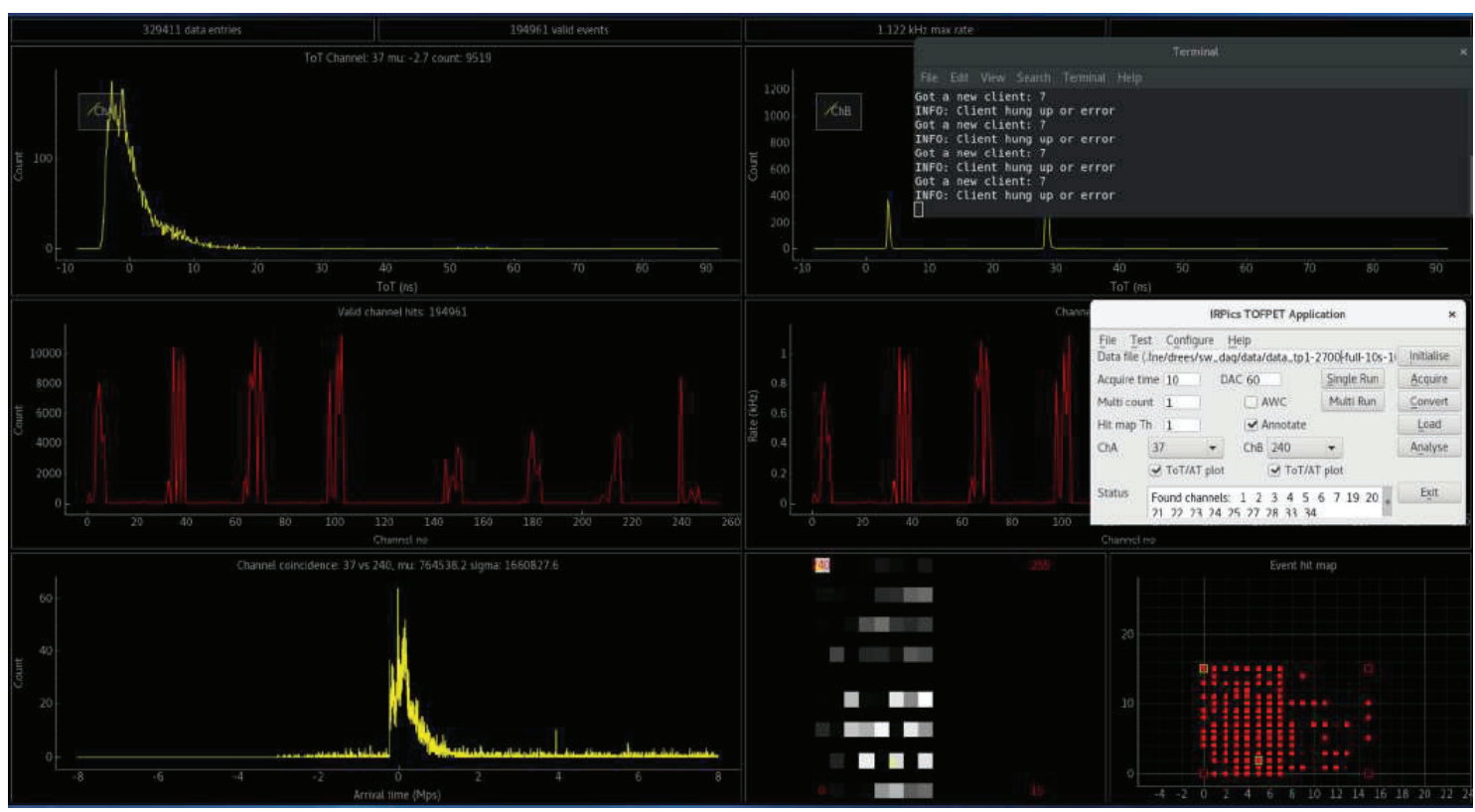

Signal versus range. Image - the white spot (37) is a tree at 600 metres.

The atmospheric signal at short range is strongly enhanced by the mist / fog.

There is a weak but easily measured signal return at $\sim 4 \mathrm{msec}$ (arrow to right) from the tree. 


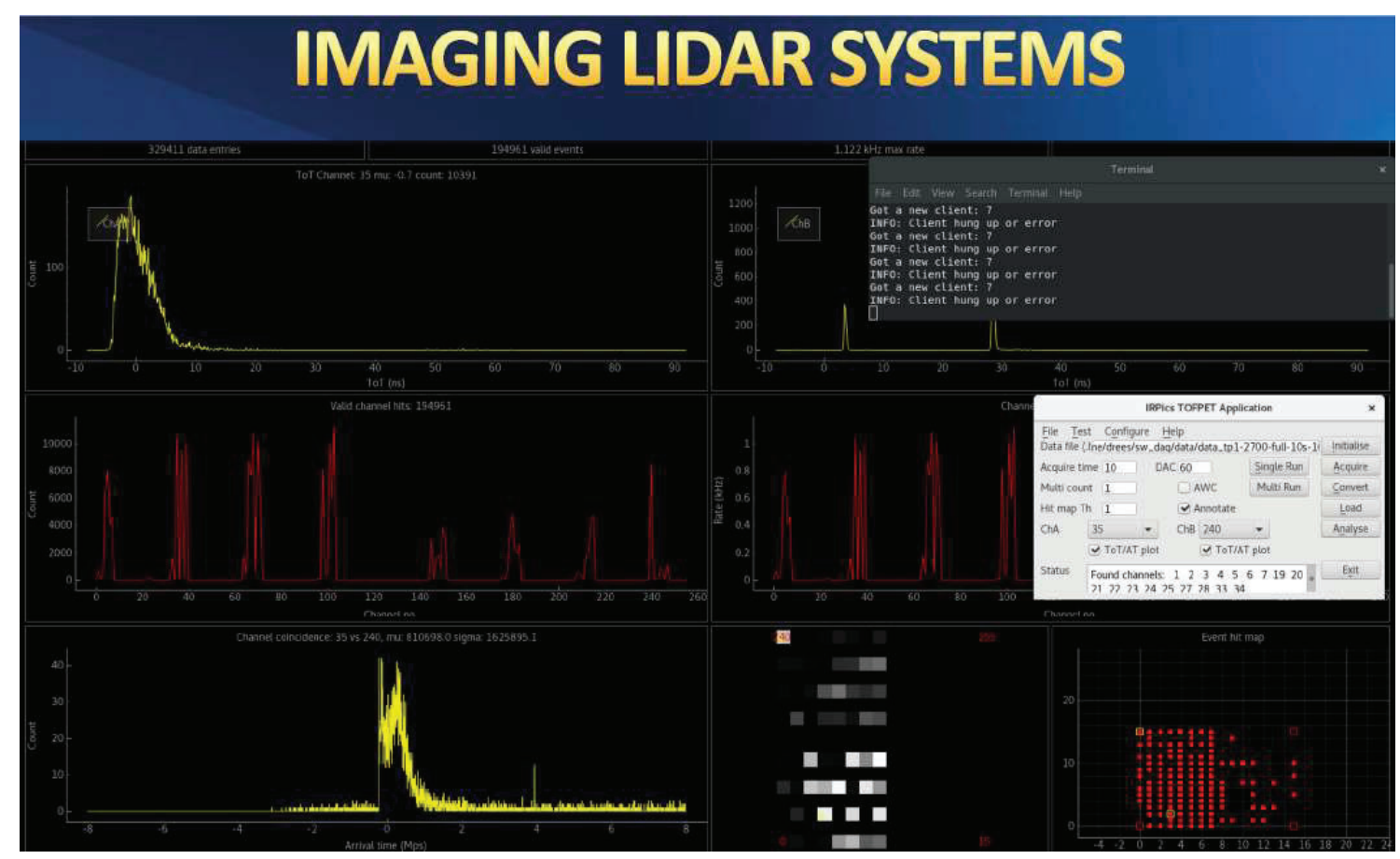

Signal versus range. Image - the white spot (35) is a tree at 600 metres.

This image, at 22:42 UT, shows the back-scattered signal return from pixel 35.

The atmospheric signal at short range is strong (enhanced by the mist/ fog).

There is a weak but easily measured signal return at $4 \mathrm{msec}$ (to right) from the tree

\section{Current and Future Developments:}

A $64 * 64$ element version of the current photo-detector has already been built.

However, the development of the sophisticated processing electronics currently lags the development of the photo-tube by a significant factor!!

\section{Image Resolution:}

The $32 * 32$ image may be deconvolved to provide $128 * 128$ element resolution;

The future generation of $64 * 64$ element detector we believe will be capable of providing $512 * 512$ element resolution via deconvolution.

\section{SUMMARY}

This presentation is intended to demonstrate the state of art of Imaging Lidar Systems appropriate for future ground-based / airborne and Space-based Missions.

The technologies required in terms of space-qualifiable lasers, detectors and signal processing electronics have matured dramatically during the last decade.

These are the enabling steps required for the future productive exploitation of these Imaging Lidar Systems.

A number of examples of data from space and ground-based systems have been used to demonstrate that these are now practical and affordable possibilities. 